\title{
What are the needs of patients following discharge from hospital after an acute exacerbation of chronic obstructive pulmonary disease (COPD)?
}

\section{*Kevin Gruffydd-Jones ${ }^{\mathrm{a}, \mathrm{b}}$, Carol Langley-Johnson ${ }^{\mathrm{c}}$, Christopher Dyer , Kathryn Badlan ${ }^{\mathrm{d}}$, Sabbi Warda}

a Box Surgery, Box, Wiltshire, SN13 8NA, UK

${ }^{b}$ University of Bath, UK

c Wiltshire Primary Care Trust, UK

d University of West-of-England, Bristol, UK

Received 14th November 2006; accepted 8th August 2007

\begin{abstract}
Aim: To identify patient needs following discharge from hospital after an exacerbation of COPD.

Methods: Qualitative and semi-quantitative study using home-based structured interviews and focus groups involving 25 COPD patients after hospital discharge. Interviews were performed seven days and three months post-discharge. Quantitative data were analysed using descriptive statistics and were triangulated with the qualitative data from interviews and the focus groups.

Results: There were high levels of depression (64\%) and anxiety (40\%). Feelings of anxiety after discharge were associated with the fear of another "attack" and with uncertainties about social and medical care provision, especially the provision of oxygen.

Conclusions: Interventions to reduce readmission for COPD exacerbations need to consider the psychosocial as well as the medical needs of patients. There appears to be a need for improved hospital discharge procedures and community follow-up - including the provision of pulmonary rehabilitation and encouragement of self-management strategies.

(c) 2007 General Practice Airways Group. All rights reserved

K Gruffydd-Jones, et al. Prim Care Resp J 2007; 16(6): 363-368.

doi:10.3132/pcrj.2007.00075
\end{abstract}

Keyw ords COPD exacerbations, primary care, patients' needs

\section{Introduction}

Hospital admissions for exacerbations of chronic obstructive pulmonary disease (COPD) are associated with high economic costs as well as costs to individual patients. Patients admitted for COPD accounted for 1 million bed days in NHS Hospitals in England in 2004/2005. 'There is a clinically significant decrease in health status after three or more COPD exacerbations. ${ }^{2}$ Fifteen percent of patients die and $31 \%$ are readmitted within three months of admission to hospital with an exacerbation of COPD. ${ }^{3}$

Several approaches have been used, with mixed results, in an attempt to reduce this burden of hospital readmission. A self-management programme as part of an overall supported package of care has been shown to reduce readmission rates, ${ }^{4}$ although a Cochrane review of self-management plans showed no influence on hospital admissions. ${ }^{5}$ Early assisted discharge and "hospital at home" schemes have been shown to reduce the number of in-patient days without compromising morbidity; however, they do not reduce the rate of readmission. ${ }^{6}$ Post-discharge pulmonary rehabilitation has been shown to reduce hospital readmission. ${ }^{7}$

Previous interventions have often excluded a high proportion of patients (up to $60 \%$ in the early discharge schemes) because of disease severity, co-morbidity or social factors. It may be that interventions have to be tailored more to individual patient needs in order to be successful in preventing readmission. There is a paucity of literature exploring these needs. This study aims to look at the

*Corresponding author: Tel: +44 (0)1225 742361 Fax: +44 (0)1225 742646 E-mail: Kevin.Gruffydd-Jones@gp-J83013.nhs.uk 
Figure 1. Flow chart for Study.

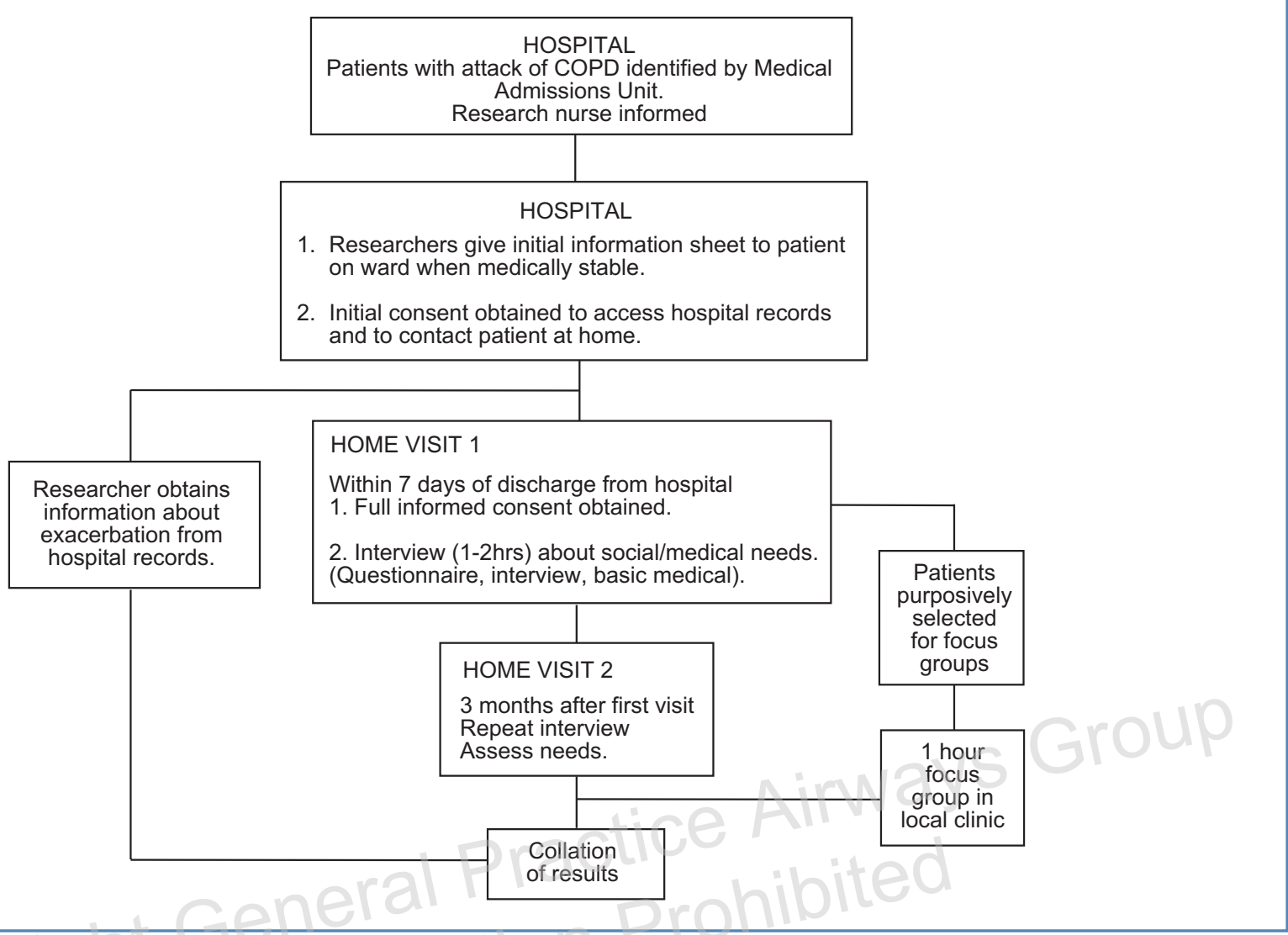

characteristics of patients who have been discharged from hospital after an exacerbation of COPD, and to look at their individual medical and psychosocial needs immediately after discharge and three months later. The results will be used to plan an active intervention arm in a randomised controlled trial aimed at reducing hospital readmission for exacerbations of COPD.

\section{Methods}

Design

A prospective observational study using semi-quantitative and qualitative data from interviews and focus groups.

\section{Study population}

Patients were included into the study following admission with a principal diagnosis of an acute exacerbation of COPD to a District General Hospital (DGH) in the South-West of England - an area covered by two primary care trusts (PCTs) between 1st Dec 2005 and 31st March 2006. The hospital does not operate an early discharge scheme. Generic community support teams exist in the PCT areas, but there is no specialist respiratory support post-discharge. Figure 1 shows an overview of the study and method of recruitment.

Patients were excluded if they were unwilling or unable to give informed consent. Patients were deemed unable to give informed consent if they were unable to communicate effectively with the interviewers due to physical illness (e.g altered consciousness) or mental illness (e.g abbreviated mental test score $<7 / 10$ ).

\section{Data collection}

Patients were interviewed at home within seven days of discharge from hospital (Visit 1) and were then visited three months later (Visit 2). The following data were collected:

1. Quantitative data about the events surrounding admission and discharge, demographic, psychosocial and morbidity data (such as oximetry, Medical Research Council (MRC) dyspnoea score, health status, Hospital Anxiety and Depression (HAD) Scale scores, and co-morbidity) were collected prospectively during the home interviews by structured questionnaires. Further details surrounding the admission and discharge procedure were obtained by a retrospective analysis of hospital records. Quantitative data were analysed using descriptive statistics.

2. Qualitative data, obtained from; a) a semi-structured questionnaire assessing patient needs (see Appendix 1 at www.thepcrj.org); b) focus groups.

Two focus groups were convened by two researchers experienced in qualitative research. Patients were selected for 
the focus groups by purposive sampling designed to reflect heterogeneity of disease severity and geographical spread.

The aims of the focus groups were:

- To explore the participants' journey through a period of exacerbation (in-patient experience)

- To explore the experiences of the participants postdischarge

- To understand the issues which were significant and meaningful to these participants

Open questions to explore experiences on discharge were used to trigger discussion. These were derived from the aims above and the process was iterative. Interviews were transcribed and thematically analysed using the framework for Interpretative Phenomenology as described by Smith et al. ${ }^{8}$ Four major themes were identified and there was a high degree of concurrence between the facilitators. These themes were then triangulated with those emerging from the analysis of the home interview data. Findings were similar and included three of the four major themes. In order to ascertain whether these findings were recognisable to the participants (so as to enhance the credibility of the interpretation ${ }^{9,10}$ ) a summary of themes was returned to them for their comments.

\section{Table 1. Social characteristics of the patients.}

\begin{tabular}{|c|c|c|}
\hline Mean aqe $\left(95 \% \mathrm{Cl}^{*}\right)$ & \multicolumn{2}{|l|}{$76(72.4-79.4)$} \\
\hline Gender & $11 \mathrm{M} 14 \mathrm{~F}$ & \\
\hline Smoking status & \multicolumn{2}{|c|}{ Current - 2; Never - 5; Ex - 20} \\
\hline Median admissions in & \multicolumn{2}{|l|}{$1(0-4.5)$} \\
\hline last year $(\mathrm{IQR} * *)$ & \multicolumn{2}{|c|}{ *1 patient had 15 admissions } \\
\hline Patients with admissior & & \\
\hline last 3 months & $9(36 \%)$ & \\
\hline \multirow[t]{3}{*}{ Marital status } & Widowed & $11(44 \%)$ \\
\hline & Married & $9(36 \%)$ \\
\hline & Single & $5(20 \%)$ \\
\hline \multirow[t]{3}{*}{ Domicilary status } & Lives alone & $11(44 \%)$ \\
\hline & Lives with family/friend & $12(48 \%)$ \\
\hline & Nursing/residential home & $2(8 \%)$ \\
\hline \multirow[t]{6}{*}{ Main Carer } & Spouse & $9(36 \%)$ \\
\hline & Family living-out & $6(24 \%)$ \\
\hline & Social Services & $5(20 \%)$ \\
\hline & Live-in family & $2(8 \%)$ \\
\hline & No carer & $1(4 \%)$ \\
\hline & Friend & $1(4 \%)$ \\
\hline
\end{tabular}

* $95 \% \mathrm{Cl}=95 \%$ confidence limits $\quad * * \mathrm{QQR}=$ Interquartile range

\section{Results \\ Recruitment}

One hundred and forty-five patients were admitted with a diagnosis of COPD exacerbation over the study period. Ninety-five patients were excluded because they did not live in the reference PCT areas, and in 10 patients the discharge diagnosis was different - for example, pneumothorax. Two patients refused consent.

Thirty-eight patients were initially consented for the study whilst still in hospital. However, six were not contactable after discharge, four were admitted to a community hospital after discharge but prior to visit 1 and couldn't be interviewed, and three died prior to Visit 1.

\section{Visit 1}

Therefore, 25 patients were available for interview at a median of seven days post-discharge (IQR 5-10 days). Sixteen patients were approached to take part in focus groups but only six consented, giving two groups of three people.

Tables 1 and 2 show the social and medical characteristics of the patients, respectively. Table 3 shows the details surrounding the discharge of the patient from hospital.

Table 2. Medical characteristics of patients postdischarge.

\begin{tabular}{ll} 
Mean body mass index (BMI) (95\% CI) & $23(22-24)$ \\
\% Oxygen saturation (on air) & 9 patients $\leq 92 \%$ \\
Median MRC Dyspnoea Score (IQR*) $)^{11}$ & $5(4-5)$ \\
Median AQ20 ${ }^{12}$ (health status) (IQR) & $9(6-12)$ \\
Median HAD (Anxiety) Score ${ }^{13}(\mathrm{IQR})$ & $7(5-10)(10$ patients $\geq 8)$ \\
Median HAD (Depression) Score ${ }^{13}(\mathrm{IQR})$ & $9(6-10)(16$ patients $\geq 8)$ \\
Previous pneumovac & $23(92 \%)$ \\
Influenza vaccination in last year & $24(96 \%)$ \\
Previous pulmonary rehabilitation & $11(44 \%)$ \\
& 7 in the community \\
\hline SELF MANAGEMENT PLANS ISSUED & $2(4 \%)$ \\
Standby steroids issued & $6(24 \%)$ \\
Standby antibiotics issued & $5(20 \%)$ \\
\hline MEDICATION & $16(84 \%)$ \\
Oral steroids (acute) & $12(48 \%)$ \\
Patients on oxygen & 3 on long term oxygen \\
Patients on inhaled steroids (all in & $14(56 \%)$ \\
combination with beta-2 agonist) & $16(64 \%)$ \\
Patients with nebulisers & $23(92 \%)$ \\
Patients with spacers & \\
* Interquartile range &
\end{tabular}


Table 3. Details surrounding the admission and discharge.

\begin{tabular}{|c|c|c|}
\hline Mean days in hospital $\left(95 \% \mathrm{Cl}^{*}\right)$ & \multicolumn{2}{|l|}{$6.9(5.5-8.3)$} \\
\hline Discharge destination & Nursing/residential home & $3(12 \%)$ \\
\hline \multirow[t]{2}{*}{ Median days before discharge letter sent to GP (IQR**) } & \multicolumn{2}{|l|}{$4(1-13)$} \\
\hline & \multicolumn{2}{|c|}{ ( 6 patient letters had a delay of $>3$ weeks and 1 was delayed for 77 days) } \\
\hline \multirow[t]{5}{*}{ Professional contact since discharge } & No contact & $12(48 \%)$ \\
\hline & District/practice nurse & $7(28 \%)$ \\
\hline & "Other" (friend/Age Concern) & $5(20 \%)$ \\
\hline & Respiratory liaison nurse & $2(8 \%)$ \\
\hline & Social worker & $1(4 \%)$ \\
\hline
\end{tabular}

\section{Visit 2}

Only 14 out of the original 25 patients were interviewed at Visit 2; two patients died between Visits 1 and 2, two patients had been re-admitted to hospital (due to COPD exacerbations) and seven were not contactable or had moved. Between Visits 1 and 2 there was a $28 \%$ readmission rate.

The characteristics of the follow-up group at Visit 2 were similar - in particular, all but one patient had MRC scores of 3 and above and might have benefited from pulmonary rehabilitation. No patients had received, or were planned to receive, pulmonary rehabilitation post-discharge. Five out of 14 patients (35\%) remained depressed according to the HAD questionnaire.

\section{Perceived problems at Visit 1}

The most common problems expressed by 8 patients (32\%) were feelings of uncertainty about what was going on and feeling isolated. Three patients felt traumatised mentally by the experience of being in hospital. Four patients expressed concerns about the availability of oxygen therapy. In reply to direct prompts, 20 patients (80\%) said they had persisting problems with breathlessness and 16 (64\%) had problems with cough. Tiredness was seen as a problem by 21 patients (84\%) and 12 (48\%) had troublesome ankle swelling.

When asked about problems with their everyday lives, 13 patients (52\%) admitted to problems with everyday activities. Concerns were expressed about care (lack of care, and isolation) and a minority had concerns about which allowances (such as Disability Allowance) they were entitled to. Table 4 shows the answers to the question "What would make life easier for you?" The main concerns are around provision of oxygen and information about its use $(20 \%$ of patients) and around social needs of care, benefits, and
Table 4. Responses to the question "What would make life easier for you?".

Response Number of patients

Oxygen provision/clarity about existing provision $5(20 \%)$ Help at home $3(12 \%)$

Advice about social benefit entitlement $4(16 \%)$ Alternative housing $2(8 \%)$ Nebuliser provision

More visits from health professionals

$2(8 \%)$

Advice on what to do in a flare-up

$1(4 \%)$

housing ( $26 \%$ of patients).

\section{Themes from focus groups}

The following themes emerged from the focus groups:

1. Reluctance to seek medical help in an exacerbation.

This centred around feelings of "not wanting to bother my GP because I know how busy he is," fears around being admitted to hospital, and also a perception that things would get better by themselves.

2. Fear and anxiety associated with acute attacks of breathlessness.

This was a major issue for patients, especially the fear of waking up at night feeling breathless. Uncertainty was also expressed about who to contact in the middle of the night during attacks of breathlessness. Linked to this was a lack of knowledge about how and when oxygen could be provided in the community in such situations.

For example;

Mr. R; "How ill do you have to be before you can get oxygen?" 
Facilitator; "How ill do you have to be?"

Mr. R; "Yes you got to be dead?"

3. Follow-up after hospital.

Concerns were expressed about the lack of discharge planning, with problems getting transport home from hospital and then anxiety on arriving home. This centred around an uncertainty about medical and social support and how they would manage if they became breathless again. A feeling of isolation was expressed and a desire to have a visit from a nurse or doctor "to check up on me." $\mathrm{Mr} \mathrm{H}$; "I er came out (of hospital) on Saturday I think it was and on Monday the GP came to see me..."

Facilitator;"What are the good things about him coming to see you?"

$\mathrm{Mr}$. H; "Re-assurance of er that I'm still in touch with medical people. Wanted to let me know that the medication's fine and I er really needed to know this."

Concerns were expressed about the lack of time that social services could provide support at home and there were language difficulties with some carers.

4. Educational needs.

Patients felt that they needed more help about what to do when symptoms deteriorated and were especially concerned about the provision of standby oral steroids and antibiotics. In particular, there was some confusion about the provision and use of home oxygen.

\section{Discussion}

This study explores the characteristics and perceived needs of patients after discharge from a DGH in the South-West of England following an exacerbation of COPD, and the gaps in care across two Wiltshire PCTs.

One criticism of this study is that, with small subject numbers from a single location, the results are not generalisable. However, the numbers recruited are similar to other qualitative work in this therapeutic area ${ }^{14}$ and the patient characteristics are similar to those patients included by Ram et al in their review of early discharge schemes ${ }^{6}-$ i.e. older adults (mean age 76 ) with a high readmission rate (36\% patients) of whom many were living alone (44\%). The number of patients in the focus groups (six) is small due to difficulties in recruitment because of transport problems and fears about getting breathless - typical of this patient population. The focus groups may therefore not be representative of the total study group which may include some patients who were housebound.

There was a $28 \%$ readmission rate in the three months following hospital discharge - due solely to exacerbations of COPD and not to any other co-morbid condition - and considerably fewer patients available for interview at Visit 2 (at three months post-discharge) as compared to Visit 1 (seven days post-discharge). Direct comparisons between the two interview groups are therefore difficult (for example, the more severe patients may have died ) but the patient characteristics at Visit 1 and Visit 2 are similar.

The needs of this group of patients following hospital discharge after an exacerbation of COPD appear to fall into three categories;

\section{Psychological needs}

There were high levels of anxiety, fear and uncertainty associated with the exacerbation following discharge from hospital. The focus groups highlight the feelings of anxiety and fear associated with breathlessness especially in the middle of the night. In spite of this there was a median delay of seven days from the onset of symptoms to hospital admission. There was confusion about when to call for help, but also a reluctance to "bother the doctor" and a perception that "things would get better". This reluctance to consult was similarly found by Adams et $\mathrm{al}^{14}$ and may be due to a more stoical attitude of an older generation (Patient J; "The awful thing about this generation - it was brought up not to whinge, not to whine.... You know to get on with it".)

For many the process of discharge from hospital left them feeling anxious and confused about what was going on, and many felt isolated. Almost half of the patients had had no professional medical or social contact one week after admission. This may well have been caused by the delay in sending out hospital discharge letters, with almost a quarter of patients having letters sent three weeks after discharge.

Formal testing with the HAD questionnaire confirms high levels of anxiety and depression with 16 patients (64\%) being significantly depressed (HAD(D) score $\geq 8$ ). The presence of anxiety and depression has been shown to be independently associated with poor health status in patients hospitalised for COPD. ${ }^{15}$ In turn, the presence of poor health status and anxiety increases the risk of readmission with an exacerbation of COPD. ${ }^{16}$ Further research needs to be carried out to look at the effects of treating depression and anxiety on readmission rates.

\section{Social needs}

Over a third of patients (36\%) expressed concerns about social provision, especially the provision of care, housing and uncertainties about social benefits. Sixty percent of patients stated that their main carer was a member of their family. Twenty percent were cared for principally by social services. Thirty percent expressed concern about the health of their carer, and concerns about communication problems with non-native English-speaking carers provided by social services was an issue. The needs of carers should be considered in any future intervention or research.

\section{Medical needs}

The medical profile of these patients reveals a high degree of 
breathlessness (median MRC score $=5$ ). One of the PCTs has been running a pulmonary rehabilitation programme for five years - hence the figure of $44 \%$ of patients having had pulmonary rehabilitation is relatively high. However, the high MRC scores indicate that more people may have benefited from pulmonary rehabilitation, which has been shown to reduce readmission rates when given post-discharge ${ }^{7}$ and to reduce length of in-patient stay when given in the non-acute setting. ${ }^{17}$

There was a broad spectrum of co-morbidity, with hearing and joint problems predominating. Unexpectedly there did not appear to be a high prevalence of co-morbid cardiovascular disease.

The UK COPD (NICE) Guidelines ${ }^{11}$ recommend the use of combination inhaled corticosteroid/long-acting beta-2 agonist (ICS/LABA) inhalers in patients with two or more COPD exacerbations and a forced expiratory volume in one second $\left(\mathrm{FEV}_{1}\right)$ value of $\leq 50 \%$ predicted. Although lung function was not measured in this study, $44 \%$ patients were not on combination inhaled therapy.

Nine out of 24 patients (38\%) had oxygen saturations of $\leq 92 \%$ in air yet only three were receiving long-term oxygen therapy (LTOT), which may indicate possible under-referral for assessment for oxygen therapy. The provision of oxygen was a recurrent theme throughout the study; many patients had found oxygen to be of help in relieving breathlessness and anxiety during an exacerbation. Patients perceived that there was a need for oxygen therapy following hospital discharge, but were uncertain why it hadn't been provided, or - if it had been provided - when they should use it.

\section{Conclusion}

This group of COPD patients, recently discharged from hospital after an acute exacerbation of COPD, exhibit a variety of psychosocial and medical needs. In particular, there appears to be a need for personalised self-management advice (when and how to call for help) and better education on the use of oxygen. There appears to be a need for increased use of combination ICS/LABA therapy, pulmonary rehabilitation and anti-depressant therapy. Further research is planned which will look at whether or not interventions, designed to meet these needs, can reduce the high readmission rate of patients with COPD exacerbations.

\section{Ethics approval}

The Study was approved by the North Bristol Research Ethics Committee.

\section{Funding}

Funding for this study was provided by the Pan-Bath and Swindon Research Collaborative.

\section{Conflict of interest declaration}

Kevin Gruffydd-Jones has provided consultancy and speaker services for the following pharmaceutical companies: Boehringer Ingelheim, Pfizer, AstraZeneca, GlaxoSmithKline, Altana, Novartis, IVAX, Galen, MSD, and Schering Plough. Christopher Dyer has provided speaker services for GlaxoSmithKline. Kathryn Badlan, Carol Langley-Johnson and Sabbi Ward have no potential conflicts of interest.

\section{References}

1. The Burden of Lung Disease. 2nd Edition. A report from the British Thoracic Society 2006.

2. Seemungal TAR, Donaldson GC, Bestall DJ, Jeffries DJ, Wedzicha JA. Effects of exacerbations on Quality of Life in patients with chronic obstructive airways disease. Am J Respir Crit Care Med 1998;157:1418-22.

3. Price IC, Lowe D, Hasker H, Anstey K, Pearson MG, Roberts CM. The UK National COPD Audit 2003: impact of hospital resources and organisation of care on patient outcome following admission for acute COPD exacerbation. Thorax 2006;61(10):837-43.

4. Gadoury MA, Scwartzman K, Rouleau M, et al. Self-management reduces both short and long-tem hospitalisation in COPD. Eur Resp Journal 2005;26(5):8537.

5. Turnock AC, Walters EH, Walters JAE, Wood-Baker R. Action Plans for chronic obstructive pulmonary disease. Cochrane Database Systematic Review 2005 October 19(4)

6. Ram FS, Wedzicha JA, Wright J, Greenstone M. Hospital at Home for patients with acute exacerbations of chronic obstructive airways disease: systematic review of the evidence. BMJ 2004;329:315-18.

7. Puhan MA, Scharlplatz M, Troosters $T$, et al. Respiratory rehabilitation after acute exacerbation of COPD may reduce risk for readmission and mortality-a systematic review. Respiratory Research 2005;6:54.

8. Smith JA, Harre R, Langenhove L. Rethinking Methods in Psychology. London: Sage Publications 1995.

9. Sandelowski. M. The problem of rigor in qualitative research. ANS Adv Nurs Sci 1986;8:27-37.

10. Krefting L. Rigor in qualitative research: The assessment of trustworthiness. Am J Occup Ther 1991;45:214-22.

11. National clinical guideline on management of chronic obstructive pulmonary disease in adults in primary and secondary care. Thorax 2004,59 Supp 1.

12. Hajiro T, Nishimuru K, Jones PW, et al. A novel, short and simple questionnaire to measure quality-of life in patients with chronic obstructive pulmonary disease. Am J Respir Crit Care Med 1999;59:1874-6.

13. Dowson C, Laing R, Barraclough R, et al. The use of the Hospital Anxiety and Depression Scale (HADS) in patients with chronic obstructive pulmonary disease: a pilot study. N Z M ed J 2001;114(1141):447-9.

14. Adams R, Chavannes N, Jones K, Stubbe Ostergard M, Price D. Exacerbations of chronic obstructive pulmonary disease - a patients' perspective. Prim Care Resp J 2006;15:102-09. doi:10.1016/j.pcrj.2006.01.003

15. Gudmundsson G, Gisalason T, Janson C, et al. Depression, anxiety and health status after hospitalisation for COPD: a multi-centre study in the Nordic Countries. Respir Med 2006;100(1):87-93.

16. Gudmundsson $G$, Gislason $T$, Janson $C$, et al. Risk Factors for re-hospitalisation in COPD: role of health status, anxiety and depression. Eur Respir J 2005;3 414-19.

17. Griffiths TL, Phillips CJ, Davies S, Burr ML, Campbell IA. Cost effectiveness of an outpatient multidisciplinary pulmonary rehabilitation programme. Thorax 2001;56(10):779-84.

\section{Available online at http://w w w.thepcrj.org}

